\title{
Breast cancer in neurofibromatosis type 1: overrepresentation of unfavourable prognostic factors
}

Elina Uusitalo ${ }^{1}$, Roope A Kallionpää ${ }^{1}$, Samu Kurki ${ }^{2}$, Matti Rantanen ${ }^{3}$, Janne Pitkäniemi ${ }^{3,4}$, Pauliina Kronqvist ${ }^{5}$, Pirkko Härkönen ${ }^{1}$, Riikka Huovinen ${ }^{6}$, Olli Carpen ${ }^{2,5,7}$, Minna Pöyhönen ${ }^{8,9}$, Sirkku Peltonen ${ }^{10}$ and Juha Peltonen*,1 ${ }^{1}$ Department of Cell Biology and Anatomy, University of Turku, Kiinamyllynkatu 10, 20520 Turku, Finland; ${ }^{2}$ Auria Biobank, University of Turku and Turku University Hospital, Kiinamyllynkatu 8, 20520 Turku, Finland; ${ }^{3}$ Finnish Cancer Registry-Institute for Statistical and Epidemiological Cancer Research, Unioninkatu 22, 00130 Helsinki, Finland; ${ }^{4}$ Department of Public Health, Faculty of Medicine, University of Helsinki, Helsinki, Finland; ${ }^{5}$ Department of Pathology, University of Turku and Turku University Hospital, Kiinamyllynkatu 10, 20520 Turku, Finland; 'Department of Oncology and Radiotherapy, Turku University Hospital, PB 52, 20521 Turku, Finland; ${ }^{7}$ Department of Pathology, University of Helsinki and Helsinki University Hospital, PB 67, 00014 Helsinki, Finland; ${ }^{8}$ Department of Clinical Genetics, HUSLAB, Helsinki University Central Hospital, PB 160, 00029 Helsinki, Finland; ${ }^{9}$ Department of Medical and Clinical Genetics, University of Helsinki, Helsinki, Finland and ${ }^{10}$ Department of Dermatology, University of Turku and Turku University Hospital, PB 52, 20521 Turku, Finland

Background: An increased breast cancer incidence and poor survival have been reported for women with neurofibromatosis 1 (NF1). To explain the poor survival, we aimed to link the histopathology and clinical characteristics of NF1-associated breast cancers.

Methods: The Finnish Cancer Registry and the Finnish NF Registry were cross-referenced to identify the NF1 patients with breast cancer. Archival NF1 breast cancer specimens were retrieved for histopathological typing and compared with matched controls.

Results: A total of 32 breast cancers were diagnosed in 1404 NF1 patients during the follow-up. Women with NF1 had an estimated lifetime risk of $18.0 \%$ for breast cancer, and this is nearly two-fold compared with that of the general Finnish female population (9.74\%). The 26 successfully retrieved archival NF1 breast tumours were more often associated with unfavourable prognostic factors, such as oestrogen and progesterone receptor negativity and HER2 amplification. However, survival was worse in the NF1 group $(P=0.053)$ even when compared with the control group matched for age, diagnosis year, gender and oestrogen receptor status. Scrutiny of The Cancer Genome Atlas data set showed that NF1 mutations and deletions were associated with similar characteristics in the breast cancers of the general population.

Conclusions: These results emphasise the role of the NF1 gene in the pathogenesis of breast cancer and a need for active followup for breast cancer in women with NF1.

Neurofibromatosis type 1 (NF1) is an autosomal dominant cancer syndrome with a birth incidence as high as 1:2000 (Huson et al, 1989; Uusitalo et al, 2015). The most common features are café au lait pigment macules, skinfold freckles and cutaneous as well as plexiform neurofibromas (Riccardi and Eichner, 1986). Epidemiologic studies have reported a 2.7 to 5 times higher risk for cancer in NF1 compared with the general population (Sørensen et al, 1986; Zöller et al, 1997; Walker et al, 2006; Seminog and Goldacre, 2013; Uusitalo et al, 2016). Tumours typical in NF1 include intracranial gliomas and malignant peripheral nerve sheath tumours (MPNST). In addition to neoplasms

*Correspondence: Professor J Peltonen; E-mail: juhpel@utu.fi 
originating from the nervous system, other aggressive tumours, such as gastrointestinal stromal tumours (GIST) and pheochromocytomas, are related to NF1 (Walther et al, 1999; Maertens et al, 2006; Uusitalo et al, 2016). The cancer survival of NF1 patients has also been reported to be inferior to that of cancer patients without NF1 syndrome (Uusitalo et al, 2016).

There are numerous case reports on NF1 and breast cancer, but less than half a dozen reports containing data that allow generalisation of the results (Sharif et al, 2007; Madanikia et al, 2012; Wang et al, 2012; Seminog and Goldacre, 2015). The data suggest an increased incidence for breast cancer in NF1. We have recently published a population-based study that showed beyond doubt an elevated risk for breast cancer in NF1 (Uusitalo et al, 2016). In the study by Uusitalo et al (2016), 21.8\% of all observed cancer events in female NF1 patients were breast cancers. In particular, female NF1 patients under the age of 40 years have breast cancer incidence that is $>10$ times that of the general Finnish population (Uusitalo et al, 2016). The NF1 patients also have elevated breast cancer mortality and poor breast cancer survival (Evans et al, 2011; Uusitalo et al, 2016).

The NF1 syndrome is caused by mutations in the NF1 gene that encodes neurofibromin, the main function of which is to facilitate the conversion of active Ras-GTP to inactive Ras-GDP (Xu et al, 1990; Scheffzek et al, 1997). Comparative oncogenomics implicates the NF1 as a driver gene in breast cancer (Wallace et al, 2012). Every fourth breast cancer case in The Cancer Genome Atlas (TCGA) data set was reported to harbour a deletion or mutation in the NF1 gene (Wallace et al, 2012). The NF1 mutations and deletions are even more prevalent in HER2 (human epidermal growth factor receptor 2) -amplified and basal tumour subtypes of breast cancer.

Breast cancer is a heterogeneous group of tumours with a variable prognosis. The most important prognostic factors are tumour grade, tumour size, regional lymph nodes status, proliferation index, oestrogen receptor (ER) and progesterone receptor (PR) status and amplification of the HER2 gene (Finek et al, 2007). The same factors are used as predictive for the treatment of individual patients with breast cancer (Coates et al, 2015). The intrinsic breast cancer subtypes have been established based on gene expression profiles (Perou et al, 2000). At the molecular level, breast cancers may be classified into luminal A, luminal B, HER2-amplified and triple-negative or basal-like cancers. Luminal A and B are both ER/PR-positive types, but luminal B may also display HER2 amplification and high Ki-67 expression. The HER2 subtype is negative for ER and PR and shows HER2 amplification. Triple-negative (ER -, PR - and HER2 - ) breast cancers form an aggressive subtype and a part of these tumours, the basal-like type, express cytokeratins of the basal epithelial layer, such as cytokeratin 5/6 (CK5/6) and cytokeratin 14 (CK14; Coates et al, 2015).

The current study was designed to elucidate the biological and clinical features associated with the poor survival of NF1-associated breast cancer in terms of histopathology and clinical characteristics.

\section{MATERIALS AND METHODS}

Patients. The study adhered to the Declaration of Helsinki principles and was approved by the Ethics Committee of the Southwest Finland Hospital District, Finland's Ministry of Social Affairs and Health and the National Supervisory Authority for Welfare and Health (Valvira). A research permit was obtained from each participating hospital.

The Finnish NF Registry is population-based and has been previously described in detail (Uusitalo et al, 2015, 2016). The NF1 cohort of the current study comprises 1404 NF1 patients (20 248 person-years of follow-up) from the 5 university and 15 central hospitals in Finland. The NF1 patients were followed up for breast cancer starting from the date of the first hospital visit due to NF1 between 1987 and 2011 and ending at death, emigration or 31 December 2013, whichever occurred first. Of the 1404 patients, 737 were female and 667 male. The NF1 cohort was crossreferenced with the Finnish Cancer Registry (http://www.cancer.fi/ syoparekisteri/en/) to find all NF1 patients with a breast cancer diagnosis. Follow-up information on life status and emigration of the patients was obtained from the Cause of Death Registry and Population Register Centre. The Cancer Registry search revealed 49 breast cancers diagnosed in 45 females and 1 male with NF1. Two of the female and the male patient had two primary breast cancers. Out of the 49 , a total of 32 breast cancers had been diagnosed in the NF1 cohort during follow-up.

Tumour samples. Archival surgery specimens of the available NF1 female breast tumours and clinical information related to the samples (including tumour size and the lymph node status at the time of surgery) were retrieved from the pathology units of the participating hospitals. Search was restricted to invasive breast carcinomas, and only one breast cancer was included in the case of two separate breast cancer diagnoses. Formalin-fixed, paraffinembedded breast cancer tissue samples from 26 NF1 breast cancer patients diagnosed in 1992-2011 were available for analysis.

Histology, immunohistochemistry and in situ hybridisation. Sections, $3 \mu \mathrm{m}$ thick, were cut from the formalin-fixed, paraffinembedded breast cancer tissue samples and stained with haematoxylin and eosin (HE) for histological analysis. The HEstained breast tumour slides were reviewed for histological type and grade of each tumour according to the WHO classification of tumours of the breast (Lakhani et al, 2012). The TNM classification of malignant tumours was used to grade the extent of spread of the breast carcinomas (Lakhani et al, 2012).

Immunolabelling for ER, PR, Ki-67, CK5/6, CK14 and HER2 was performed using a BenchMark XT automated immunostaining instrument (Roche/Ventana, Tucson, AZ, USA) and ultraView Universal DAB Detection Kit. Sections for HER2 amplification testing were selected on the basis of immunohistochemistry, and gene amplification was thereafter confirmed with in situ hybridisation (Coates et al, 2015). The HER2/Chr17 double in situ hybridisation was performed with the BenchMark XT using the Ventana HER2 DNA probe, Inform Chromosome 17 probe, ultraView SISH detection kit to detect HER2 and the ultraView Alkaline Phosphatase Red ISH Detection Kit to detect Chr17. All reagents were from Roche/Ventana. The ISH Protease 3 for $8 \mathrm{~min}$ was used as a pretreatment step, and HER2 hybridisation was performed at $52{ }^{\circ} \mathrm{C}$ for $6 \mathrm{~h}$ and $\mathrm{Chr} 17$ hybridisation at $44^{\circ} \mathrm{C}$ for $2 \mathrm{~h}$. The cutoff for ER and PR positivity was nuclear immunoreactivity in $>10 \%$ of tumour cells.

The breast cancers were classified into subgroups following these recommendations (Coates et al, 2015):

- 'Luminal A' = ER/PR +, HER2 - , Ki-67 < 14\%

- 'Luminal B'=(1) ER+, HER2 + or (2) ER+, HER2 -, and either Ki-67 $>14 \%$ or PR -

- 'HER2 subtype' $=\mathrm{ER}-, \mathrm{PR}-$, HER2 +

- 'Triple-negative' $=\mathrm{ER}-, \mathrm{PR}-, \mathrm{HER} 2-$

- 'Basal-like' = ER -, PR - , HER2 - , CK5 + .

Case-control analysis of tumour characteristics. A case-control analysis for tumour type and grade was used to study the characteristics of the 26 NF1 breast cancer cases. For each NF1 breast cancer, five age- and sex-matched controls without NF1 were randomly sampled from the data of Auria Biobank, Turku, Finland (https://www.auriabiopankki.fi/?lang=en). Auria Biobank 
hosts archived diagnostic specimens obtained from patients attending the Turku University Hospital for diagnosis and treatment of conditions requiring biological cell or tissue specimens. The catchment population is $\sim 500000$ people. The biobank retrieves clinical information associated with the samples from the hospital electronic health records. The control breast cancer samples had been analysed in the same clinical laboratory and using practically the same methods as the NF1 samples.

The clinical and tissue-based tumour parameters were compared between the NF1 group and the control group. The tissuebased parameters included histological grade, size of the primary tumour (pT), number of metastatic lymph nodes (pN), Ki-67 positivity, presence of ER- and PR-positive cancer cells and HER2 amplification.

NF1 alterations in breast cancers of the general population. In order to evaluate the occurrence and relevance of alterations in the NF1 gene in breast cancers of the general population, we used data generated by the TCGA Research Network (http://cancergenome.nih.gov/; accessed 7 October 2016). This database contains somatic mutations and copy number alterations detected in tumours together with several clinical characteristics of the cancers and patients. Invasive breast carcinomas included in the TCGA data set were classified by NF1 status. Samples with normal NF1 were compared with those that harboured a mutation or some level of deletion in NF1.

Statistical methods and survival. Follow-up for cancer through the population-based country-wide Finnish Cancer Registry was done automatically using the personal identity code as a key. Standardised incidence ratios (SIRs) of breast cancer were calculated as the ratios of observed to expected cases, where the expected cases were obtained by multiplying the number of person-years with the corresponding population rate stratified by age group, calendar period and gender. The 95\% confidence intervals (CIs) were based on the assumption that the number of observed cases followed the Poisson distribution. The cumulative lifetime risk (risk by the age of 85 years) and age group-specific risk (the probability of developing breast cancer at given age range for those alive and not diagnosed with breast cancer before) for breast cancer was estimated by applying the method of competing risks (mortality) with allowance for delayed entry.

Tumour characteristics coded either as binary or ordinal variables were analysed using generalised linear mixed effects models (GLMM; Demidenko, 2013). The grouping variable (NF1 or control) was the main exposure variable of interest. In order to compare NF1 patients and controls matched for age and sex, the grouping variable that indexed matched sets was included as a random effect in the GLMM. The 5-year breast cancer survival was studied with a five-fold randomly chosen control group without NF1. The controls were also retrieved from Auria Biobank and they were matched with the NF1 study group for age, breast cancer diagnosis year, gender and oestrogen receptor status $(+/-)$. The patients were followed from the time of breast cancer surgery to death or to the end of the follow-up (31 December 2013). Cumulative survival proportions were estimated using the KaplanMeier method, and the NF1 and control groups were compared using matched Cox's regression model. The data satisfied the proportional hazards assumption of Cox's regression.

The TCGA breast cancers with a normal or mutated/deleted NF1 were compared using the $\chi^{2}$ test for tumour characteristics and the Cox proportional hazards model for survival outcome analysis.

All statistical analyses were conducted using the statistical software R versions 3.2.2-3.3.0 (The R Foundation; https://www.rproject.org/) with lme4 (version 1.1-11), ordinal (version 2015.6-28), popEpi (version 0.2.1) and survival (version 2.38-3) packages.

\section{RESULTS}

NF1 patients with breast cancer. Cross-referencing the population-based Finnish NF Registry (Uusitalo et al, 2015, 2016) with the Finnish Cancer Registry resulted in a total of 49 breast cancers diagnosed in 45 females and 1 male with NF1. Two of the female patients and the male patient had two primary breast cancers diagnosed 8.3-19.6 years apart. The youngest NF1 patient was 28 and the oldest was 84 years old at the time of diagnosis (median 49 years). A total of 31 breast cancers were diagnosed in NF1 females and 1 in NF1 male during the follow-up period.

In reference to the known risk factors for breast cancer, 14 out of the 45 NF1 women (31\%) were nulliparous, whereas 24 (53\%) patients had had at least one birth before age 30 years. The respective numbers among NF1 women without breast cancer were $38 \%$ and $52 \%(P=0.458$ and $P=0.951$, respectively). The BRCA1/ 2 mutations were not systematically tested, but in the three patients where this had been done, no BRCA1/2 mutations were detected; this included the one NF1 male with breast cancer. Ovarian cancer was not detected in any of the NF1 patients with breast cancer.

Risk for breast cancer in NF1 women. The SIR of breast cancer was calculated using data from the Finnish Cancer Registry. A total of 31 breast cancers were observed in the female NF1 cohort during the follow-up, yielding a SIR of 2.82 (Table 1). The SIR for breast cancer was highest in the youngest age groups: for women $<40$ years it was 14.25 , whereas in women aged $40-50$ years it was 2.60. The SIR of breast cancer was not significantly increased in the age groups of $>50$ years.

The cumulative risk for breast cancer in NF1 women by age of 40 years was $4.7 \%$ (95\% CI $1.6-7.6 \%)$ and by age 50 years $7.8 \%$ (95\% CI 3.9-11.5\%). The respective numbers in the Finnish population are $0.45 \%$ and $2.1 \%$. The estimated lifetime risk for breast cancer in NF1 women was $18.0 \%$ (95\% CI 11.4-24.1\%) compared with $9.7 \%$ in the general population. Women with NF1 had a $4.7 \%$ (95\% CI 1.5-7.9\%) risk of being diagnosed with breast cancer during 30-39 years of age, whereas the corresponding risk of the general population is only $0.34 \%$ (Table 2 ).

Histopathology, subtypes and clinical characteristics of NF1 breast cancer. Archival breast cancer tissue specimens were obtained from 26 invasive breast cancers of female NF1 patients who were 29 to 84 years old at the time of the breast cancer surgery (median age 53 years). Of the breast tumours, $88.5 \%$ were ductal carcinomas and $7.7 \%$ lobular carcinomas. The breast cancer tumours were profiled using immunolabelling for ER, PR, Ki-67, CK5/6 and CK14, and in situ hybridisation for HER2. The breast cancer subtype was luminal A in $15.4 \%$ of the NF1 samples, luminal B in $34.6 \%$, HER2 amplified in $30.8 \%$ and triple-negative in $19.2 \%$. The basal-like phenotype was seen in $15.4 \%$. The subtypes and immunohistochemistry of NF1 breast cancer specimens are shown in Table 3 by age groups. The results showed that the HER2-amplified subtype was the most common in the age group of $<40$ years ( 3 out of 6 ). In the age group of $40-50$ years,

Table 1. Standardised incidence ratio (SIR) for NF1 female breast cancer by age group

\begin{tabular}{|l|c|c|r|l|c|}
\hline Age group & Observed & Expected & SIR & $95 \%$ Cl & $P$-value \\
\hline$<40$ Years & 9 & 0.63 & 14.25 & $6.51-27.04$ & $<0.001$ \\
\hline $40-49$ Years & 6 & 2.31 & 2.60 & $0.95-5.65$ & 0.0359 \\
\hline $50-59$ Years & 8 & 3.75 & 2.13 & $0.92-4.20$ & 0.0532 \\
\hline$\geqslant 60$ years & 8 & 4.30 & 1.86 & $0.80-3.66$ & 0.1231 \\
\hline Total & 31 & 11.00 & 2.82 & $1.92-4.00$ & $<0.001$ \\
\hline
\end{tabular}


the luminal B type was the most frequent (4 out of 6 ), whereas in the age group of $>50$ years, the different types were more evenly represented. Grade III was the most frequent grade in both the youngest and the oldest age groups.

Comparison of breast cancer characteristics between NF1 and controls. The breast cancer characteristics were compared between the NF1 patients and matched controls (Table 4). The results showed that the NF1 breast cancers were more often ER negative $(53.8 \%$ vs $20.9 \%, P=0.001)$ and $\mathrm{PR}$ negative $(65.4 \%$ vs $21.7 \%, P<0.001)$. The HER 2 amplification was overrepresented in the NF1 group $(30.8 \%$ vs $9.6 \%, P=0.006)$. The NF1 breast cancers were larger in size $(P=0.019)$ by TNM classification and of higher grade $(P=0.050$; Table 4$)$.

Survival. Out of the 26 NF1 patients, 11 (42.3\%) died during the follow-up. Survival was similar in the cases where tissue samples could not be retrieved (data not shown). Because the NF1 breast cancers were more often ER negative, survival analysis was carried out using a control group matched for age, breast cancer diagnosis year, gender and ER status. The overall survival was worse in the NF1 group: 5year survival was $68.1 \%$ (95\% CI 52.0-89.1\%) in the NF1 group and $82.0 \%$ (95\% CI $75.5-88.9 \%)$ in the control group $(P=0.053)$. This yielded a hazard ratio of 2.34 (95\% CI $0.99-5.6$; Figure 1$)$.

Relevance of NF1 alterations in breast cancers of the general population. Mutations or deletions of the NF1 gene were observed

Table 2. The risk of breast cancer in different age groups

\begin{tabular}{|l|c|c|c|}
\cline { 2 - 4 } & \multicolumn{2}{c|}{ NF1 women } & Finnish women \\
\cline { 2 - 4 } Age group & Risk (\%) & $\mathbf{9 5 \% ~ C l ~}$ & Risk (\%) \\
\hline $20-29$ & 0.55 & $0.00-1.62$ & 0.03 \\
\hline $30-39$ & 4.74 & $1.48-7.89$ & 0.34 \\
\hline $40-49$ & 3.92 & $0.77-6.96$ & 1.50 \\
\hline $50-59^{\text {a }}$ & 5.89 & $1.86-9.76$ & 2.64 \\
\hline $60-69^{\text {a }}$ & 4.18 & $0.09-8.11$ & 2.88 \\
\hline $70-79$ & 3.99 & $0.00-9.26$ & 2.44 \\
\hline $\begin{array}{l}\text { Abbreviations: } \mathrm{Cl}=\text { confidence interval; NF1 = neurofibromatosis 1. } \\
\text { a'Women aged 50-69 years are routinely invited to mammography screening in Finland. }\end{array}$ \\
\hline
\end{tabular}

in $33 \%$ of the TCGA breast cancers. Patients with an NF1 deletion or mutation in the tumour were slightly younger than those with an intact NF1 (56.8 vs 59.2 years, $P=0.013$ ). The NF1 mutations and deletions were associated with decreased survival: 5-year survival was $86.5 \%$ (95\% CI 81.7-91.6\%) for the breast cancer patients with a normal NF1 gene status, but only $77.1 \%$ (95\% CI 70.5-84.3\%) for those with an NF1 mutation or deletion (hazard ratio $1.85,95 \%$ CI $1.14-3.00, P=0.014)$. Comparisons of the receptor status showed a pattern similar to the one of NF1 patients: cancers with an NF1 mutation or deletion were significantly more often ER and PR negative and HER2 amplified than cancers with a normal NF1 gene $(P<0.001$ for all). Restricting the analysis to NF1 mutations only resulted in a similar trend in survival (hazard ratio $3.2,95 \%$ CI $1.1-9.0, P=0.031)$ and receptor status. However, the differences in ER and HER2 status were not significant $(P=0.223$ and $P=0.196$, respectively) because of the low number of tumours $(n=26)$ in the TCGA data set harbouring NF1 mutation.

\section{DISCUSSION}

The main findings of this study are that NF1 breast cancers are often associated with poor survival and unfavourable prognostic factors, such as ER and PR negativity and HER2 amplification. The study also shows, however, that the poor prognosis of the NF1related breast cancer is not explained by histopathological subtype only.

The study utilised two comprehensive population-based registers: the Finnish Neurofibromatosis Registry (Uusitalo et al, 2015, 2016) and the Finnish Cancer Registry. It is reasonable to assume that all Finnish NF1 patients who have had breast cancer during the follow-up are included. Our results show that the breast cancer incidence in NF1 women aged $<40$ years is increased with a cumulative risk of $4.7 \%$. This is 10 -fold compared with the control population $(0.45 \%)$, and corroborates our previous findings that young patients with NF1 have a high SIR for breast cancer (Uusitalo et al, 2016). Yet, half of the NF1 breast cancers were diagnosed in women over 50 years where the incidence is moderately increased compared with the general population.

We were not able to retrieve information on all common breast cancer risk factors for our patients, but we do not assume that our

\begin{tabular}{|c|c|c|c|c|}
\hline Patient age & $\begin{array}{c}\text { All patients } \\
n \text { (\%/all) }\end{array}$ & $\begin{array}{c}\text { Age }<40 \\
n(\% / \text { age group) }\end{array}$ & $\begin{array}{c}\text { Age 40-50 } \\
\text { n (\%/age group) }\end{array}$ & $\begin{array}{c}\text { Age }>50 \\
n(\% / \text { age group) }\end{array}$ \\
\hline n (\%/all) & $26(100 \%)$ & 6 (23.1\%) & $6(23.1 \%)$ & 14 (53.8\%) \\
\hline $\begin{array}{l}\text { Histological type } \\
\text { Ductal } \\
\text { Lobular } \\
\text { Other }\end{array}$ & $\begin{aligned} & 23(88.5 \%) \\
& 2(7.7 \%) \\
& 1(3.8 \%)\end{aligned}$ & & & \\
\hline $\begin{array}{l}\text { Breast cancer subtype } \\
\text { Luminal A } \\
\text { Luminal B } \\
\text { HER2 subtype } \\
\text { Basal-like } \\
\text { Triple-negative, other than basal-like }\end{array}$ & $\begin{array}{l}4(15.4 \%) \\
9(34.6 \%) \\
8(30.8 \%) \\
4(15.4 \%) \\
1(3.8 \%)\end{array}$ & $\begin{array}{c}0 \\
2(33.3 \%) \\
3(50.0 \%) \\
1(16.7 \%) \\
0\end{array}$ & $\begin{array}{c}1(16.7 \%) \\
4(66.7 \%) \\
1(16.7 \%) \\
0 \\
0\end{array}$ & $\begin{array}{l}3(21.4 \%) \\
3(21.4 \%) \\
4(28.6 \%) \\
3(21.4 \%) \\
1(7.1 \%)\end{array}$ \\
\hline $\begin{array}{l}\text { Ki-67 } \\
\quad<20 \% \\
>20 \%\end{array}$ & $\begin{array}{c}9(34.6 \%) \\
17(65.4 \%)\end{array}$ & $\begin{array}{l}1 \text { (16.7\%) } \\
5 \text { (83.3\%) }\end{array}$ & $\begin{array}{l}3(50.0 \%) \\
3(50.0 \%)\end{array}$ & $\begin{array}{l}5 \text { (35.7\%) } \\
9 \text { (64.3\%) }\end{array}$ \\
\hline $\begin{array}{l}\text { Grade } \\
\text { | } \\
\text { II }\end{array}$ & $\begin{array}{c}1(3.8 \%) \\
11(42.3 \%) \\
14(53.8 \%)\end{array}$ & $\begin{array}{c}0 \\
2(33.3 \%) \\
4(66.7 \%)\end{array}$ & $\begin{array}{c}0 \\
4(66.7 \%) \\
2(33.3 \%)\end{array}$ & $\begin{array}{c}1(7.1 \%) \\
5(35.7 \%) \\
8(57.1 \%)\end{array}$ \\
\hline
\end{tabular}


findings are because of general risk factors, such as overweight, nulliparity, alcohol or smoking. For example, 53\% of the patients had given birth at least once by age 30 years, and parity is associated with a decreased risk for breast cancer (Hsieh et al, 1994; Rosner et al, 1994; Kobayashi et al, 2012). Our conclusion is that $\mathrm{NF} 1$ patients share a common cancer risk factor that is a mutation in the NF1 tumour suppressor gene. Thus, the accumulation of a sufficient number of mutations required for malignancy may occur earlier in NF1 syndrome.

The NF1 gene aberrations are also frequent in breast cancers in patients who do not have the NF1 syndrome and the NF1 gene might be a general driver in breast cancer (Wallace et al, 2012). Wallace et al (2012) reported NF1 alterations especially in HER2enriched and basal subtypes where over $40 \%$ of the tumours harboured NF1 mutations or deletions. The number of cases included in the TCGA data set has since increased, and our analysis of the TCGA data set, with the NF1 gene as the starting point, shows that NF1 mutations and deletions are associated with similar characteristics in terms of breast cancer receptor status and survival in the general population as those in NF1 patients. Of the TCGA breast tumours with NF1 deletion, 85\% also harboured deletion of BRCA1 that is located on the same chromosome as

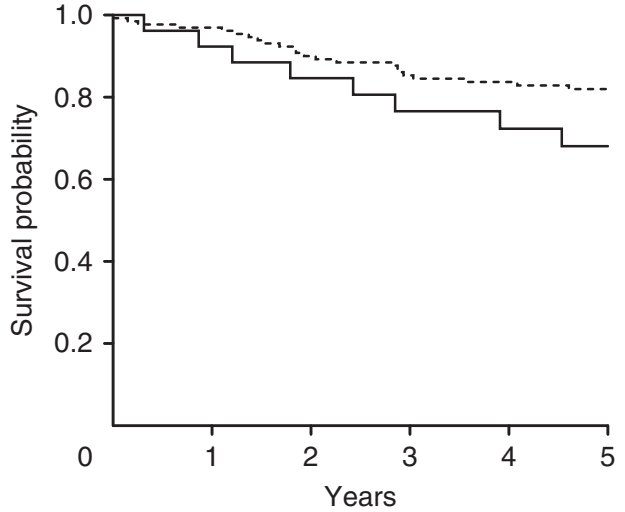

No. at risk:

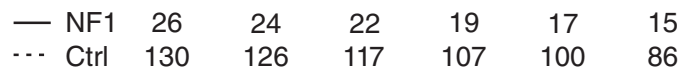

Figure 1. Survival of NF1 breast cancer patients and age, year of the diagnosis, sex and oestrogen receptor status (+/ $)$-matched control breast cancer patients, $P=0.053$. Numbers of NF1 patients and controls at risk are shown below the figure.

Table 4. Comparison of NF1 and control breast cancers by grade, pT class, lymph node and receptor statuses and the proliferative index $\mathrm{Ki}-67$

\begin{tabular}{|c|c|c|c|c|}
\hline & NF1 group, $n(\%)^{a}$ & Control group, $n(\%)^{a}$ & OR $(95 \% \mathrm{Cl})^{b}$ & $P$-value \\
\hline Total & 26 & 130 & & \\
\hline $\begin{array}{l}\text { Tumour grade } \\
\text { I } \\
\text { II } \\
\text { III } \\
\text { Unknown }\end{array}$ & $\begin{array}{c}1(3.8 \%) \\
11(42.3 \%) \\
14(53.8 \%) \\
0\end{array}$ & $\begin{array}{c}21(18.4 \%) \\
49(43.0 \%) \\
44(38.6 \%) \\
16\end{array}$ & $2.37(1.00-5.61)$ & $P=0.050$ \\
\hline $\begin{array}{l}\text { PT class } \\
1 \\
2 \\
3 \\
4 \\
\text { Unknown }\end{array}$ & $\begin{array}{c}11(42.3 \%) \\
13(50.0 \%) \\
1(3.8 \%) \\
1(3.8 \%) \\
0\end{array}$ & $\begin{array}{c}78(66.1 \%) \\
34(28.8 \%) \\
6(5.1 \%) \\
0(0.0 \%) \\
12\end{array}$ & $2.87(1.19-6.90)$ & $P=0.019$ \\
\hline $\begin{array}{l}\text { Lymph node status } \\
\text { N0 } \\
\text { N1 } \\
\text { N2 } \\
\text { N3 } \\
\text { Unknown }\end{array}$ & $\begin{array}{c}11(44.0 \%) \\
10(40.0 \%) \\
3(12.0 \%) \\
1(4.0 \%) \\
1\end{array}$ & $\begin{array}{c}53(55.2 \%) \\
30(31.3 \%) \\
10(10.4 \%) \\
3(3.1 \%) \\
34\end{array}$ & $1.53(0.65-3.61)$ & $P=0.332$ \\
\hline $\begin{array}{l}\text { Progesterone receptor status } \\
\text { Positive (10-100\%) } \\
\text { Negative (0-10\%) } \\
\text { Unknown }\end{array}$ & $\begin{array}{c}9(34.6 \%) \\
17(65.4 \%) \\
0\end{array}$ & $\begin{array}{c}90(78.3 \%) \\
25(21.7 \%) \\
15\end{array}$ & $0.10(0.03-0.29)$ & $P<0.001$ \\
\hline $\begin{array}{l}\text { HER2 amplification } \\
\text { Yes } \\
\text { No } \\
\text { Unknown }\end{array}$ & $\begin{array}{c}8(30.8 \%) \\
18(69.2 \%) \\
0\end{array}$ & $\begin{array}{c}11(9.6 \%) \\
104(90.4 \%) \\
15\end{array}$ & $5.46(1.67-20.11)$ & $P=0.006$ \\
\hline $\begin{array}{l}\text { Triple-negative } \\
\text { Yes } \\
\text { No } \\
\text { Unknown }\end{array}$ & $\begin{array}{c}5(19.2 \%) \\
21(80.8 \%) \\
0\end{array}$ & $\begin{array}{c}15(13.0 \%) \\
100(87.0 \%) \\
15\end{array}$ & $1.65(0.48-5.09)$ & $P=0.399$ \\
\hline
\end{tabular}


NF1. Thus, some effects may be unspecific and because of copy number alterations of $B R C A 1$ or other nearby genes. However, restricting the analysis to NF1 mutations showed similar pattern in terms of survival and receptor status. The concordance between breast cancers of NF1 patients and TCGA breast tumours with NF1 mutations or deletions, or mutations only, suggests that these effects may be associated with the NF1 gene.

Breast cancer of young women is generally associated with a worse prognosis and a higher incidence of unfavourable clinicopathological features (Adami et al, 1986; Nixon et al, 1994; Anders et al, 2008; Sheridan et al, 2014) than of older women. These features include lack of ER, larger tumour size, more frequent HER2 amplifications, wider local spread to lymph nodes, higher tumour grade and a trend towards poorer disease-free survival (Anders et al, 2008). Because young patients were overrepresented in the NF1 group in our study, we also expected to find these characteristics in NF1 breast cancers. However, it was surprising to note that breast cancers of NF1 patients were even more often associated with unfavourable prognostic factors, such as ER and PR loss and HER2 amplification, than breast cancers of age- and sexmatched controls. The proportion of HER2 subtype in breast cancers in women $<50$ years has been reported to be $12 \%$ (Sihto et al, 2008), but in our study it was 33\% (4 out of 12). However, these characteristics alone do not explain the poor survival of the NF1 patients with breast cancer.

The poor prognosis of NF1 breast cancer patients may also partly be because of advanced stage at the time of diagnosis. The breast cancers of the NF1 patients were larger and of higher grade at the time of surgery, although the slightly worse lymph node status of NF1 patients was not statistically significant. It has been speculated that subcutaneous neurofibromas may interfere with the clinical diagnostic workup of breast cancer (Evans, 2012; Da Silva et al, 2015) and this might cause a delay in NF1 breast cancer diagnosis. However, the results of the present study show that diagnostic delay of NF1-related breast cancer - if present - does not explain the characteristics of NF1 breast cancers. The TCGA breast cancers are independent of NF1 disease manifestations, but they still show an association between poor survival, unfavourable prognostic factors and NF1 mutations/deletions.

The mechanism by which loss of NF1 function is associated with a poor outcome of breast cancer patients is probably caused by uninhibited Ras signalling via the PI3K and Raf/MAPK/ERK pathways. Increased PI3K activity has often been related to poor survival and resistance to hormone treatment in ER-negative breast cancer (Yang et al, 2016), whereas elevated Ras/MAPK/ ERK activity has been related to metastasis and poor survival in both ER-positive luminal (Wright et al, 2015) and ER-negative breast cancer (Giltnane and Balko, 2014). In the absence of inhibition by NF1, enhanced and prolonged Ras stimulation by cell membrane tyrosine kinase receptors such as EGFR and HER2 can activate, via the Raf/MAPK/ERK pathway, several transcription factors, such as c-myc and ETS1. These pathways and factors are involved in stimulation of cell proliferation, viability, epithelial-mesenchymal transition, migration and invasion (Giltnane and Balko, 2014), the effects of which may strongly facilitate breast cancer development and progression in NF1 patients ( $R a d$ and Tee, 2016).

Although the material is unique, the number of archival samples was relatively small $(n=26)$ to make definitive conclusions in cancer that has five subgroups. However, the differences in distribution of receptors statuses were statistically highly significant. The survival analysis is based on all-cause mortality, as the causes of death were not available for the controls. However, 7 of the $8 \mathrm{NF} 1$ patients who died during the 5-year period used in the survival analysis had breast cancer as the cause of death and no other comorbidities contributing to the death recorded in the death certificates.
The results of the current study highlight the question of the surveillance strategy for NF1 breast cancer. Tung et al (2016) have suggested intensified monitoring by mammography for carriers of breast cancer predisposing gene variants at the age when the risk exceeds that of the general population being routinely screened. For NF1 patients, this would mean the age group of 30-39 years where the risk is $4.7 \%$ (Table 2). However, more evidence is needed on the effectiveness and safety of different screening methods in NF1 patients. Further prospective international effort is called for the elucidation of recommendations for intensified follow-up of breast cancer in NF1 patients. Currently, we suggest the following: (1) increasing the awareness of NF1 patients and their doctors of the high breast cancer risk especially in young women with NF1, (2) yearly clinical follow-up since young adulthood by doctor familiar with NF1 syndrome, and (3) any suspicion of breast cancer should warrant imaging.

Our results suggest that NF1 mutations are an independent factor contributing to poor survival of patients with breast cancer. We conclude that the awareness of the strong association between breast cancer and NF1 should affect breast cancer research in general, as NF1 also seems to be a modifier of the clinical characteristics of breast cancer in the general population without NF1.

\section{ACKNOWLEDGEMENTS}

This work was financially supported by grants from the Cancer Society of Finland (to EU, SP and JP), Finnish Cultural Foundation (to EU), Turku University Foundation (to EU) and Jalmari and Rauha Ahokas Foundation (to RAK).

CONFLICT OF INTEREST

The authors declare no conflict of interest.

\section{REFERENCES}

Adami HO, Malker B, Holmberg L, Persson I, Stone B (1986) The relation between survival and age at diagnosis in breast cancer. N Engl J Med 315: 559-563.

Anders CK, Hsu DS, Broadwater G, Acharya CR, Foekens JA, Zhang Y, Wang Y, Marcom PK, Marks JR, Febbo PG, Nevins JR, Potti A, Blackwell KL (2008) Young age at diagnosis correlates with worse prognosis and defines a subset of breast cancers with shared patterns of gene expression. J Clin Oncol 26: 3324-3330.

Coates AS, Winer EP, Goldhirsch A, Gelber RD, Gnant M, Piccart-Gebhart M, Thurlimann B, Senn HJ. Panel Members (2015) Tailoring therapiesimproving the management of early breast cancer: St Gallen International Expert Consensus on the Primary Therapy of Early Breast Cancer (2015) Ann Oncol 26: 1533-1546.

Da Silva AV, Rodrigues FR, Pureza M, Lopes VG, Cunha KS (2015) Breast cancer and neurofibromatosis type 1: a diagnostic challenge in patients with a high number of neurofibromas. BMC Cancer 15: 183.

Demidenko E (2013) Mixed Models: Theory and Applications with R. Wiley: Hoboken.

Evans DG (2012) Are we ready for targeted early breast cancer detection strategies in women with NF1 aged 30-49 years? Am J Med Genet A 158A: 3054-3055.

Evans DG, O'Hara C, Wilding A, Ingham SL, Howard E, Dawson J, Moran A, Scott-Kitching V, Holt F, Huson SM (2011) Mortality in neurofibromatosis 1: in North West England: an assessment of actuarial survival in a region of the UK since 1989. Eur J Hum Genet 19: 1187-1191.

Finek J, Holubec Jr L, Topolcan O, Elgrova L, Skalova A, Pecen L (2007) The importance of prognostic factors in premenopausal women with breast cancer. Anticancer Res 27: 1893-1896.

Giltnane JM, Balko JM (2014) Rationale for targeting the Ras/MAPK pathway in triple-negative breast cancer. Discov Med 17: 275-283. 
Hsieh C, Pavia M, Lambe M, Lan SJ, Colditz GA, Ekbom A, Adami HO, Trichopoulos D, Willett WC (1994) Dual effect of parity on breast cancer risk. Eur J Cancer 30A: 969-973.

Huson SM, Compston DA, Harper PS (1989) A genetic study of von Recklinghausen neurofibromatosis in south east Wales. II. Guidelines for genetic counselling. J Med Genet 26: 712-721.

Kobayashi S, Sugiura H, Ando Y, Shiraki N, Yanagi T, Yamashita H, Toyama T (2012) Reproductive history and breast cancer risk. Breast Cancer 19: 302-308.

Lakhani SR, Ellis IO, Schnitt SJ, Tan PH, van de Vijver MJ (2012) WHO Classification of Tumours of the Breast, Fourth Edition. International Agency for Research on Cancer: Lyon.

Madanikia SA, Bergner A, Ye X, Blakeley JO (2012) Increased risk of breast cancer in women with NF1. Am J Med Genet A 158A: 3056-3060.

Maertens O, Prenen H, Debiec-Rychter M, Wozniak A, Sciot R, Pauwels P, De Wever I, Vermeesch JR, de Raedt T, De Paepe A, Speleman F, van Oosterom A, Messiaen L, Legius E (2006) Molecular pathogenesis of multiple gastrointestinal stromal tumors in NF1 patients. Hum Mol Genet 15: $1015-1023$.

Nixon AJ, Neuberg D, Hayes DF, Gelman R, Connolly JL, Schnitt S, Abner A, Recht A, Vicini F, Harris JR (1994) Relationship of patient age to pathologic features of the tumor and prognosis for patients with stage I or II breast cancer. J Clin Oncol 12: 888-894.

Perou CM, Sørlie T, Eisen MB, van de Rijn M, Jeffrey SS, Rees CA, Pollack JR, Ross DT, Johnsen H, Akslen LA, Fluge O, Pergamenschikov A, Williams C, Zhu SX, Lonning PE, Borresen-Dale AL, Brown PO, Botstein D (2000) Molecular portraits of human breast tumours. Nature 406: 747-752.

Rad E, Tee AR (2016) Neurofibromatosis type 1: Fundamental insights into cell signalling and cancer. Semin Cell Dev Biol 52: 39-46.

Riccardi VM, Eichner JE (1986) Neurofibromatosis: Phenotype, Natural History, and Pathogenesis. Johns Hopkins University Press: Baltimore.

Rosner B, Colditz GA, Willett WC (1994) Reproductive risk factors in a prospective study of breast cancer: the Nurses' Health Study. Am J Epidemiol 139: 819-835.

Scheffzek K, Ahmadian MR, Kabsch W, Wiesmüller L, Lautwein A, Schmitz F, Wittinghofer A (1997) The Ras-RasGAP complex: structural basis for GTPase activation and its loss in oncogenic Ras mutants. Science 277: 333-338.

Seminog OO, Goldacre MJ (2015) Age-specific risk of breast cancer in women with neurofibromatosis type 1. Br J Cancer 112: 1546-1548.

Seminog OO, Goldacre MJ (2013) Risk of benign tumours of nervous system, and of malignant neoplasms, in people with neurofibromatosis: population-based record-linkage study. Br J Cancer 108: 193-198.

Sharif S, Moran A, Huson SM, Iddenden R, Shenton A, Howard E, Evans DG (2007) Women with neurofibromatosis 1 are at a moderately increased risk of developing breast cancer and should be considered for early screening. J Med Genet 44: 481-484.

Sheridan W, Scott T, Caroline S, Yvonne Z, Vanessa B, David V, Karen G, Stephen C (2014) Breast cancer in young women: have the prognostic implications of breast cancer subtypes changed over time? Breast Cancer Res Treat 147: 617-629.

Sihto H, Lundin J, Lehtimäki T, Sarlomo-Rikala M, Bützow R, Holli K, Sailas L, Kataja V, Lundin M, Turpeenniemi-Hujanen T, Isola J,
Heikkilä P, Joensuu H (2008) Molecular subtypes of breast cancers detected in mammography screening and outside of screening. Clin Cancer Res 14: 4103-4110.

Sørensen SA, Mulvihill JJ, Nielsen A (1986) Long-term follow-up of von Recklinghausen neurofibromatosis. Survival and malignant neoplasms. N Engl J Med 314: 1010-1015.

Tung N, Domchek SM, Stadler Z, Nathanson KL, Couch F, Garber JE, Offit K, Robson ME (2016) Counselling framework for moderate-penetrance cancer-susceptibility mutations. Nat Rev Clin Oncol 13: 581-588.

Uusitalo E, Leppävirta J, Koffert A, Suominen S, Vahtera J, Vahlberg T, Pöyhönen M, Peltonen J, Peltonen S (2015) Incidence and mortality of neurofibromatosis: a total population study in Finland. J Invest Dermatol 135: 904-906.

Uusitalo E, Rantanen M, Kallionpää RA, Pöyhönen M, Leppävirta J, Ylä-Outinen H, Riccardi VM, Pukkala E, Pitkäniemi J, Peltonen S, Peltonen J (2016) Distinctive cancer associations in patients with neurofibromatosis type 1. J Clin Oncol 34: 1978-1986.

Walker L, Thompson D, Easton D, Ponder B, Ponder M, Frayling I, Baralle D (2006) A prospective study of neurofibromatosis type 1 cancer incidence in the UK. Br J Cancer 95: 233-238.

Wallace MD, Pfefferle AD, Shen L, McNairn AJ, Cerami EG, Fallon BL, Rinaldi VD, Southard TL, Perou CM, Schimenti JC (2012) Comparative oncogenomics implicates the neurofibromin 1 gene (NF1) as a breast cancer driver. Genetics 192: 385-396.

Walther MM, Herring J, Enquist E, Keiser HR, Linehan WM (1999) von Recklinghausen's disease and pheochromocytomas. J Urol 162: $1582-1586$.

Wang X, Levin AM, Smolinski SE, Vigneau FD, Levin NK, Tainsky MA (2012) Breast cancer and other neoplasms in women with neurofibromatosis type 1: a retrospective review of cases in the Detroit metropolitan area. Am J Med Genet A 158A: 3061-3064.

Wright KL, Adams JR, Liu JC, Loch AJ, Wong RG, Jo CE, Beck LA, Santhanam DR, Weiss L, Mei X, Lane TF, Koralov SB, Done SJ, Woodgett JR, Zacksenhaus E, Hu P, Egan SE (2015) Ras signaling is a key determinant for metastatic dissemination and poor survival of luminal breast cancer patients. Cancer Res 75: 4960-4972.

Xu GF, O'Connell P, Viskochil D, Cawthon R, Robertson M, Culver M, Dunn D, Stevens J, Gesteland R, White R (1990) The neurofibromatosis type 1 gene encodes a protein related to GAP. Cell 62: 599-608.

Yang SX, Polley E, Lipkowitz S (2016) New insights on PI3K/AKT pathway alterations and clinical outcomes in breast cancer. Cancer Treat Rev 45: $87-96$.

Zöller ME, Rembeck B, Odén A, Samuelsson M, Angervall L (1997) Malignant and benign tumors in patients with neurofibromatosis type 1 in a defined Swedish population. Cancer 79: 2125-2131.

(c) (1) (2) This work is licensed under the Creative Commons car ${ }_{\text {BY }}$ AA Attribution-Non-Commercial-Share Alike 4.0 International License. To view a copy of this license, visit http:// creativecommons.org/licenses/by-nc-sa/4.0/

(C) The Author(s) named above 2017 